\title{
Expression of caveolin-1 in human adipose tissue is upregulated in obesity and obesity-associated type 2 diabetes mellitus and related to inflammation
}

\author{
Victoria Catalán*, Javier Gómez-Ambrosi*, Amaia Rodríguez*, Camilo Silvał, Fernando

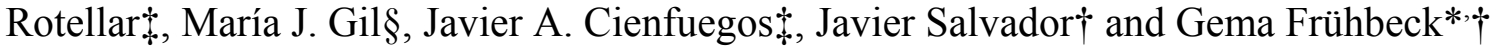

\begin{abstract}
*Metabolic Research Laboratory, $\dagger$ Department of Endocrinology, $\$$ Department of Surgery and $\S$ Department of Biochemistry, Clínica Universitaria de Navarra, University of Navarra, Pamplona, Spain
\end{abstract}

\section{SUMMARY}

Objective Caveolin-1 (CAV-1) plays important roles in many aspects of cellular biology, including vesicular transport, cholesterol homeostasis and signal transduction. The aim of the present study was to explore gene expression levels of $C A V-1$ in human adipose tissue in obesity and obesityassociated type 2 diabetes mellitus (T2DM) and to analyse its potential implication in the inflammatory state associated with obesity.

Design and methods Visceral adipose tissue (VAT) and subcutaneous adipose tissue (SAT) obtained from 15 females were used in the study. Patients were classified as lean (BMI 20.8 $\pm 1 \cdot 0$ $\mathrm{kg} / \mathrm{m}^{2}$ ) or obese $\left(\right.$ BMI $\left.50.5 \pm 2.6 \mathrm{~kg} / \mathrm{m}^{2}\right)$. The obese group was further subclassified as normoglycaemic (NG) or patients with T2DM. Anthropometric measurements as well as circulating metabolites, hormones and adipokines were determined. Real-time polymerase chain reaction (PCR) analyses were performed to quantify transcript levels of $C A V-1$ and monocyte chemoattractant protein $(M C P-1)$.

Results The presence of CAV-1 protein was detected in VAT and SAT by immunohistochemistry. Both obese NG and with T2DM patients exhibited significantly higher $C A V-1$ expression levels in VAT and SAT compared with lean subjects $(P<0.05)$. No differences between obese NG and T2DM patients were observed in VAT. However, obese T2DM patients were found to have higher $C A V-1$ expression levels in SAT $(P<0.05)$ compared with obese NG patients. A significant correlation was found between $C A V-1$ mRNA expression levels in VAT and different circulating inflammatory markers such as sialic acid $(\mathrm{SA})(P<0.001)$ and fibrinogen $(P<0.001)$ as well as with $M C P 1$ mRNA expression $(P<0 \cdot 05)$.

Conclusion Our findings show for the first time the upregulation of mRNA CAV-1 expression levels in VAT and SAT of obese NG and obese T2DM patients compared with lean controls, suggesting a role for CAV-1 in obesity and T2DM development. The association with different inflammatory markers further suggests an implication of $C A V-1$ in the low-grade inflammation accompanying obesity.

Correspondence: Dr Gema Frühbeck, Department of Endocrinology, Clínica Universitaria de Navarra, University of Navarra, Avda. Pí XII 36, 31008 Pamplona, Spain. Tel: +34 948255400 (ext. 4484); Fax: +34 948296500; E-mail: gfruhbeck@unav.es 


\section{INTRODUCTION}

Caveolae are $50-100 \mathrm{~nm}$ flask-shaped invaginations of the plasma membrane implicated in a wide range of cellular functions such as endocytosis, apoptosis, cholesterol homeostasis, proliferation and signal transduction. ${ }^{1-4}$ Caveolae are present in most cell types but they are particularly abundant in adipocytes, ${ }^{5}$ where they have been postulated to serve as a major site for the initiation of insulin signalling. ${ }^{6}$ Caveolin-1 (CAV-1), a $22 \mathrm{kDa}$ integral membrane protein, was determined to be an essential protein constituent of membrane caveolae. ${ }^{7}$

Previous studies in knockout mice show that despite being hyperphagic, adult Cav-1 null mice are lean, resistant to diet-induced obesity and exhibit reduced fat pads compared with wild type littermates. ${ }^{8}$ Furthermore, a role for CAV-1 in insulin signalling and, consequently, its potential involvement in diabetes have been put forward. ${ }^{9,10}$ It has been reported that young Cav-1 knockout mice fed a normal diet have a blunted response to an insulin tolerance test. In addition, Cav-1 knockout mice fed a high-fat diet developed significant postprandial hyperinsulinaemia. ${ }^{10}$ On further analysis, it has been reported that CAV-1 can interact with the â-subunit of the insulin receptor and enhance insulin-mediated phosphorylation of insulin receptor substrate (IRS)-1. ${ }^{11,12}$ However, this finding is controversial because other studies conclude that insulin receptor expression and signalling is independent of CAV-1 expression. ${ }^{13,14}$

Obesity and insulin resistance are associated with a chronic inflammatory response, characterized by abnormal cytokine production, increased synthesis of acute-phase reactants and the activation of proinflammatory signalling pathways. ${ }^{15-17}$ The participation of CAV-1 in the inflammatory cascade is based on its role in signal transduction via interaction with diverse elements of the inflammatory response such as endothelial nitric oxide synthase, Ras, Src and protein kinase C. ${ }^{18,19}$

As body fat (BF) represents a key peripheral organ in energy balance and given the link between obesity, insulin resistance and inflammation, ${ }^{20}$ in the present study we examined $C A V-1$ expression in human adipose tissue and its association with different markers of inflammation in a wellcharacterized group of subjects including lean, obese normoglycaemic (NG) and obese (OB) type 2 diabetes mellitus (T2DM) women.

\section{MATERIALS AND METHODS}

\section{Experimental subjects}

Paired samples of adipose tissue obtained from the omental and subcutaneous depots of 5 lean (LN) and 10 obese (OB) female individuals were used in the study. Subjects were recruited from healthy volunteers and patients attending the Endocrinology and Surgery Departments of the University Clinic of Navarra. Patients underwent a clinical assessment including medical history, physical examination, body composition analysis, comorbidity evaluation as well as nutritional interviews performed by a multidisciplinary consultation team. Patients with signs of infection were excluded. All females included in the study were in a premenopausal state. Patients were classified as obese according to both body mass index (BMI > $30 \mathrm{~kg} / \mathrm{m}^{2} ; \mathrm{LN}: 20 \cdot 8 \pm 1 \cdot 0 \mathrm{~kg} / \mathrm{m}^{2}$, OB: $50 \cdot 5 \pm 2 \cdot 6 \mathrm{~kg} / \mathrm{m}$ ) and body fat percentage (BF > $35 \%$; LN: $28 \cdot 1 \pm 3 \cdot 0 \%$, OB: $55 \cdot 2 \pm 1 \cdot 1 \%$ ). BMI was calculated as weight in kilograms divided by the square of height in meters and body fat 
was estimated by air-displacement plethysmography (Bod-Pod $\AA$, Life Measurements, Concord, CA) ${ }^{21}$ To determine the effects of T2DM on gene expression, obese volunteers were subclassified into two groups according to the presence or absence of T2DM. All lean and obese NG patients exhibited plasma glucose concentrations $<5.6 \mathrm{mmol} / \mathrm{l}$ after fasting and $<7.8 \mathrm{mmol} / 12 \mathrm{~h}$ after an oral glucose tolerance test (OGTT). Definition for T2DM was based on fasting plasma glucose concentrations $>-7.0 \mathrm{mmol} / \mathrm{l}$ or glycaemia $>-11.2 \mathrm{mmol} / \mathrm{l} 2 \mathrm{~h}$ after an OGTT. T2DM subjects were not on oral antidiabetics or other medication likely to influence endogenous insulin levels since they were first diagnosed when entering the study. The samples were collected from patients undergoing either bariatric surgery (for OB patients) or Nissen fundoplication (for LN volunteers). Both interventions were carried out via a laparoscopic approach. Tissue samples were immediately frozen in liquid nitrogen and stored at $-80{ }^{\circ} \mathrm{C}$ for gene expression analysis. The study was approved by the hospital's Ethical Committee responsible for research and informed consent of participants was obtained.

\section{Blood assays}

Plasma samples were obtained by venipuncture after an overnight fast. Glucose was analysed by an automated analyser (Hitachi Modular P800, Roche, Basel, Switzerland), with quantification being based on enzymatic spectrophotometric reactions. Insulin was measured by means of an enzymeamplified chemiluminescence assay (IMMULITE®, Diagnostic Products Corp, Los Angeles, CA).

Insulin sensitivity was calculated using the homeostasis model assessment (HOMA) [fasting glucose $(\mathrm{mmol} / \mathrm{l}) \mathrm{x}$ fasting insulin $(\mu \mathrm{U} / \mathrm{ml}) / 22 \cdot 5]$ and QUICKI $[1 /(\log$ fasting insulin $(\mu \mathrm{U} / \mathrm{ml})+\log$ fasting glucose $(\mathrm{mg} / \mathrm{dl})]$ indices. Total cholesterol concentration was determined by an enzymatic spectrophotometric method (Boehringer Mannheim, Mannheim, Germany). High-density lipoprotein (HDL) cholesterol was quantified by a colorimetric method in a Beckman Synchron $\mathbb{}$ CX analyser (Beckman Instruments Ltd, Bucks, UK). Low-density lipoprotein (LDL) cholesterol was calculated by the Friedewald formula as previously described. ${ }^{17}$

Fibrinogen concentrations were determined according to the method of Clauss using a commercially available kit (Hemoliance ${ }^{\circledR}$, Instrumentation Laboratory, Barcelona, Spain) as previously described. ${ }^{17}$ High sensitivity C-reactive protein (CRP) concentrations were quantified using the Tina-quant ${ }^{\circledR}$ CRP (Latex) ultrasensitive assay (Roche). Leptin was measured by a double-antibody radioimmunoassay (RIA) method (Linco Research Inc, St. Charles, MO). Intraand interassay coefficients of variation (CVs) were $5.0 \%$ and $4 \cdot 5 \%$, respectively. Adiponectin was determined using a commercially available ELISA kit (Biovendor, Heilderberg, Germany). Intraand interassay CVs were $6.7 \%$ and $7 \cdot 8 \%$, respectively. Monocyte chemoattractant protein (MCP1) and tumour necrosis factor-a (TNF-a) protein levels were assessed using commercially available ELISA kits ( $\mathrm{R} \& \mathrm{D}$ Systems Europe Ltd, Abingdon, UK) according to the manufacturer's instructions. The intra- and interassay CVs were $7 \cdot 8 \%$ and $6 \cdot 7 \%$ for MCP-1, and $5 \cdot 2 \%$ and $7 \cdot 4 \%$ for TNF-a, respectively. Serum amyloid A (SAA) concentrations were determined by ELISA (BioSource International Inc, Camarillo, CA), with intra- and interassay CVs being $4.9 \%$ and $7 \cdot 9 \%$, respectively. Total sialic acid (SA) was assayed using a spectrophotometric enzymatic method (Roche). 


\section{RNA extraction and real-time PCR}

Adipose tissue RNA isolation was performed by homogenization with an ULTRA-TURRAX ${ }^{\circledR}$ T 25 basic (IKA ${ }^{\circledR}$ Werke GmbH, Staufen, Germany) using TRIzol ${ }^{\circledR}$ Reagent (Invitrogen, Barcelona, Spain). Samples were purified using the RNeasy Mini kit (Qiagen, Barcelona, Spain) and treated with DNase (RNase-free DNase Set, Qiagen). For first strand cDNA synthesis constant amounts of $1 \mu \mathrm{g}$ of total RNA were reverse transcribed in a $20 \mu \mathrm{l}$ final volume using random hexamers (Roche) as primers and 200 units of M-MLV reverse transcriptase (Invitrogen) as previously described. 22,23

The transcript levels for $C A V$-1, and $M C P-1$ were quantified by real-time reverse transcription (RT)PCR (7300 Real Time PCR System, Applied Biosystem, Foster City, CA). Primers and probes were designed using the software Primer Express 1.0 (Applied Biosystems) and purchased from Proligo (Sigma-Aldrich, Lyon, France). The following primers and TaqMan probe were used for $C A V-1$ (NM_001753) amplification: forward 5'AACGATGACGTGGTCAAGATTG3', reverse 5'TCCAAATGCCGTCAAAACTGT3' and probe 5'FAMTTGAAGATGTGATTGCAGAACCAGAAGGGATAMRA3'. The primers used for MCP-1 (NM_002982) amplification were as follows: forward 5'GCTCATAGCAGCCACCTTCATT3', reverse 5'TCTGCACTGAGATCTTCCTATTGGT3' and probe 5'FAMTCGCTCAGCCAGATGCAATCAATGC-TAMRA3'. TaqMan probes encompassing fragments from extremes of two exons were designed to ensure the detection of the corresponding transcript avoiding genomic DNA amplification. The cDNA was amplified at the following conditions: 95 ${ }^{\circ} \mathrm{C}$ for $10 \mathrm{~min}$, followed by 45 cycles of $15 \mathrm{~s}$ at $95{ }^{\circ} \mathrm{C}$ and $1 \mathrm{~min}$ at $59{ }^{\circ} \mathrm{C}$, using the TaqMan ${ }^{\circledR}$ Universal PCR Master Mix (Applied Biosystems). The primer and probe concentrations for gene amplification were $300 \mathrm{nmol} / 1$ and $200 \mathrm{nmol} / \mathrm{l}$, respectively. All results were normalized to the levels of the ribosomal $18 S \mathrm{Rrna}^{24}$ (Applied Biosystems) and relative quantification was calculated using the AACt formula. Relative mRNA expression was expressed as fold expression over the calibrator sample (average of gene expression corresponding to the lean group). All samples were run in triplicate and the average values were calculated.

\section{Immunohistochemistry}

The immunohistochemistry was carried out using the indirect immunoperoxidase method. Sections (4 $\mu \mathrm{m})$ of formalin-fixed paraffin-embedded visceral adipose tissue (VAT) and subcutaneous adipose tissue (SAT) were dewaxed in xylene, rehydrated in decreasing concentrations of ethanol and treated with $3 \% \mathrm{H}_{2} \mathrm{O}_{2}$ (Sigma, Steinhein, Germany) in absolute methanol for $10 \mathrm{~min}$ at room temperature (RT) to quench endogenous peroxidase activity. Then, sections were immersed in 10 $\mathrm{mmol} / 1$ citrate buffer ( $\mathrm{pH} \mathrm{6.0)}$ ) and heated using a microwave oven at $800 \mathrm{~W}$ for $15 \mathrm{~min}$ to enhance antigen retrieval. After cooling, slides were blocked during $1 \mathrm{~h}$ with $1 \%$ murine serum (Sigma) diluted in Tris-buffer saline (TBS) $(50 \mathrm{mmol} / \mathrm{l}$ Tris, $0.5 \mathrm{~mol} / 1 \mathrm{NaCl} ; \mathrm{pH} 7 \cdot 36)$ to prevent nonspecific adsorption. Sections were incubated overnight at $4{ }^{\circ} \mathrm{C}$ with rabbit anticaveolin-1 (Sigma) antibody diluted $1: 100$ in TBS. After three washes (5 min each) with TBS, sections were incubated with horseradish peroxidase conjugated antirabbit (Amersham Biosciences, Little Chalfont, Buckinghamshire, UK) polyclonal IgG diluted $1: 100$ in TBS for $30 \mathrm{~min}$ at RT. After washing in TBS, peroxidase reaction was visualized with a $3 \cdot 3$ 'diaminobenzidine (DAB, Amersham Biosciences) and/or $\mathrm{H}_{2} \mathrm{O}_{2}$ solution $\left(0.5 \mathrm{mg} / \mathrm{ml}\right.$ DAB, $0.03 \% \mathrm{H}_{2} \mathrm{O}_{2}$ diluted in 50 
$\mathrm{mmol} / \mathrm{l}$ Tris-HCl, $\mathrm{pH} 7 \cdot 36$ ), as chromogen and Harris haematoxylin solution (Sigma) as counterstaining. Sections were dehydrated, cover-slipped and observed under a Zeiss Axiovert $40 \mathrm{CFL}$ optic microscope (Zeiss, Göttingen, Germany). Negative control slides without primary antibody were included to assess nonspecific staining.

\section{Data analysis}

Data are presented as mean \pm standard error of the mean (SEM). SAA values did not follow a normal distribution and were logarithmically transformed for statistical analysis. These values are presented as median (interquartile range). Differences between groups were assessed by one-way analysis of the variance (ANOVA) followed by least significant difference (LSD) tests. Pearson's correlation coefficients $(r)$ were used to analyse the association between variables. The calculations were performed using the SPSS for Windows version 13.0 statistical package (SPSS, Chicago, IL). A $P$-value $<0.05$ was considered statistically significant.

\section{RESULTS AND DISCUSSION}

A summary of biochemical and hormonal characteristics of the subjects is shown in Table 1. The obese patients included in our study showed significantly higher BF $(P<0.01)$ and leptin concentrations $(P<0.05)$, together with lower HDL-cholesterol levels $(P<0.01)$ when compared with the lean volunteers. Obese T2DM patients had significantly increased glucose concentrations in the fasting state $(P<0.01)$ and $2 \mathrm{~h}$ after an OGTT $(P<0.01)$ in comparison with NG obese volunteers, and exhibited lower concentrations of adiponectin $(P<0.05)$ in comparison with lean subjects. As expected obese NG and T2DM also showed significantly increased concentrations of inflammatory biomarkers than lean subjects: CRP $(P<0.01)$, fibrinogen $(P<0.05)$, MCP-1 $(P<$ $0 \cdot 01)$, SAA $(P<0.05)$ and TNF-a $(P<0.05)$. SA levels were only significantly increased in obese T2DM patients compared with lean volunteers $(P<0 \cdot 05)$.

Because depot-specific differences have been established as regards comorbidity development, the analyses were carried out in adipose tissue samples obtained from both the visceral and subcutaneous locations. ${ }^{25}$ The presence of CAV-1 protein in sections of VAT (Fig. 1a) and SAT (Fig. 1b) was evaluated by immunohistological analysis in obese NG and T2DM subjects. Both adipocytes and cells of the stromovascular fraction (SVF) of VAT and SAT were immunopositive for CAV-1. CAV-1 expression levels in both VAT $(P<0.05)$ and SAT $(P<0.001)$ were positively correlated to BMI and BF (Table 2). Real-time PCR analysis indicated that $C A V-1$ expression levels in VAT were significantly higher in obese NG subjects $(P=0.008)$ and obese T2DM patients $(P=$ 0.043) than in lean controls, while no differences between obese NG and T2DM patients were observed (Fig. 2). CAV-1 expression levels in SAT followed a similar trend, being significantly increased in obese NG subjects $(P=0.002)$ and obese T2DM patients $(P<0.0001)$ compared with the lean group. However, $C A V-1$ expression levels in the subcutaneous depot were higher in obese T2DM patients compared with obese NG subjects $(P=0 \cdot 027)$ (Fig. 2).

These results are in accordance with previous results in Cav-1 knockout mice, which developed progressive adipose tissue atrophy and resistance to diet-induced obesity due to an inability to gain fat mass. $^{8}$ It has been reported that white adipose tissue from $\mathrm{Cav}_{-} 1^{-/-}$mice displays heterogeneity 
in lipid droplets with a tendency towards smaller adipocytes. The smaller lipid droplets indicate that Cav-1 null adipocytes are incapable of lipogenesis during times of lipid excess. ${ }^{8}$ The significantly higher SAT and VAT expression levels of $C A V-1$ in our obese patients compared with the lean volunteers may indicate an enhanced lipid storing ability of adipocytes in human obesity. Furthermore, CAV-1 is involved not only in lipogenesis but also in the adipogenic process as $C A V$ 1 mRNA and protein levels increase over 25-fold during the differentiation of mouse 3T3-L1 fibroblasts into adipocytes, ${ }^{5}$ which is in agreement with our observed increased expression in obesity.

Insulin plays an important role in the regulation of adipose tissue homeostasis because it stimulates de novo lipogenesis as well as inhibits lipolysis. ${ }^{26,27}$ Analysis in Cav-1 knockout mice revealed a $90 \%$ decrease of detectable insulin receptor levels in adipose tissue. ${ }^{10} \mathrm{~A}$ role for CAV-1 in insulin signalling has been established.28-30 Interestingly, two mutations of the human insulin receptor located within the established CAV-1 binding motif (W1193L and W1200S) reportedly result in severe insulin resistance. ${ }^{31,32}$ In the present study T2DM patients showed higher $C A V-1$ expression levels in SAT, which may reflect an attempt to improve signalling in the setting of increased insulin resistance.

$C A V-1$ expression levels were positively correlated to $M C P-1$ mRNA in VAT $(r=0 \cdot 66, P=0 \cdot 011)$ and in SAT $(r=0.68, P=0.031) . M C P-1$ expression levels were significantly upregulated $(P<0.05)$ in VAT for both obese NG (4-5-fold) and T2DM (4-2-fold) patients compared with lean volunteers. A similar trend was found in SAT although no significant differences were observed. $C A V-1$ expression levels were positively correlated in both depots to other inflammatory markers such as plasma CRP and SA (Table 2). Moreover, a positive association of circulating concentrations of fibrinogen and SAA with $C A V-1$ mRNA in VAT was observed (Table 2). However, when the analysis was adjusted for age and BMI, only SA $(r=0 \cdot 76, P=0.007)$ and fibrinogen $(r=0 \cdot 61, P=$ 0.033 ) still retained a significant positive correlation with $C A V-1$ mRNA levels in VAT, while the significance with inflammatory markers was lost in SAT (Table 2). The production and release of inflammatory cytokines has been previously reported to be increased in VAT, ${ }^{33,34}$ suggesting that this depot is more proinflammatory. The significant correlation between circulating SAA concentrations and CAV-1 mRNA in SAT may be related to the role of this acute-phase protein in HDL-cholesterol metabolism by promoting cellular cholesterol efflux through a number of different pathways. $^{35}$ Interestingly, CAV-1 also actively plays an important role in the regulation of intracellular cholesterol homeostasis. ${ }^{36}$ The different correlation pattern between $C A V-1 \mathrm{mRNA}$ expression and proinflammatory factors observed in VAT and SAT provides further evidence for the diverse depot-specific contributions to comorbidity development. ${ }^{25}$ The more prominent involvement of SAT in lipid metabolism as opposed to VAT, which is more related to inflammation and insulin resistance, may underlie the depot-specific differences regarding the diverse correlation pattern observed in both adipose tissue locations. In our study, the association of mRNA CAV-1 levels in VAT with different inflammatory markers suggests an implication of CAV-1 in the lowgrade inflammation characteristic of visceral obesity. Elucidating the nature of this implication and the teleological significance requires further research. An involvement of CAV-1 in inflammation has been previously suggested. ${ }^{18} C A V-1$ mRNA expression has been shown to be induced by cytokines such as TNF-á and IL-1 $\hat{a}^{37}$ with numerous cytokine receptors being localized in caveolae. $^{38}$ Similar to suppressor of cytokine signalling (SOCS) proteins, CAV-1 might regulate cytokine signalling through direct interactions with members of the JAK family, associations with cytokine receptors and the proteasoma pathway. ${ }^{4,39}$ 
In conclusion, we show for the first time in humans that obesity and obesity-associated T2DM are characterized by an increased CAV-1 mRNA expression in VAT and SAT. Moreover, this expression is correlated with different inflammatory markers in VAT. Our data suggests an involvement of CAV-1 in obesity development as well as in adipose-related insulin signalling in humans. Unravelling the clinical relevance of the role of CAV-1 in these conditions remains to be fully elucidated.

\section{ACKNOWLEDGEMENTS}

This work was supported by FIS PI030381 and PI061458 from the Spanish Instituto de Salud Carlos III, Ministerio de Sanidad y Consumo and by the Department of Health of the Gobierno de Navarra (48/2003 and 20/2005) of Spain. The authors gratefully acknowledge the valuable collaboration of all surgery assistant nurses and members of the Nutrition Unit.

\section{REFERENCES}

1 Cohen, A.W., Hnasko, R., Schubert, W. \& Lisanti, M.P. (2004) Role of caveolae and caveolins in health and disease. Physiological Reviews, 84, 1341-1379.

2 Frühbeck, G. (2006) Hunting for new pieces to the complex puzzle of obesity. Proceedings of the Nutrition Society, 65, 329-347.

3 Parton, R.G. \& Simons, K. (2007) The multiple faces of caveolae. Nature Reviews Molecular Cell Biology, 8, 185-194.

4 Frühbeck, G., López, M. \& Diéguez, C. (2007) Role of caveolins in body weight and insulin resistance regulation. Trends in Endocrinology and Metabolism, 18, 177-182.

5 Scherer, P.E., Lisanti, M.P., Baldini, G., Sargiacomo, M., Mastick, C.C. \& Lodish, H.F. (1994) Induction of caveolin during adipogenesis and association of GLUT4 with caveolin-rich vesicles. Journal of Cell Biology, 127, 1233-1243.

6 Baumann, C.A., Ribon, V., Kanzaki, M., Thurmond, D.C., Mora, S., Shigematsu, S., Bickel, P.E., Pessin, J.E. \& Saltiel, A.R. (2000) CAP defines a second signalling pathway required for insulin-stimulated glucose transport. Nature, 407, 202-207.

7 Rothberg, K.G., Heuser, J.E., Donzell, W.C., Ying, Y.S., Glenney, J.R. \& Anderson, R.G. (1992) Caveolin, a protein component of caveolae membrane coats. Cell, 68, 673-682.

8 Razani, B., Combs, T.P., Wang, X.B., Frank, P.G., Park, D.S., Russell, R.G., Li, M., Tang, B., Jelicks, L.A., Scherer, P.E. \& Lisanti, M.P. (2002) Caveolin-1-deficient mice are lean, resistant to diet-induced obesity, and show hypertriglyceridemia with adipocyte abnormalities. Journal of Biological Chemistry, 277, 8635-8647.

9 Engelman, J.A., Zhang, X., Galbiati, F., Volonte, D., Sotgia, F., Pestell, R.G., Minetti, C., Scherer, P.E., Okamoto, T. \& Lisanti, M.P. (1998) Molecular genetics of the caveolin gene family: implications for human cancers, diabetes, Alzheimer disease, and muscular dystrophy. 
American Journal of Human Genetics, 63, 1578-1587.

10 Cohen, A.W., Razani, B., Wang, X.B., Combs, T.P., Williams, T.M., Scherer, P.E. \& Lisanti, M.P. (2003) Caveolin-1-deficient mice show insulin resistance and defective insulin receptor protein expression in adipose tissue. American Journal of Physiology: Cell Physiology, 285, C222-C235.

11 Yamamoto, M., Toya, Y., Schwencke, C., Lisanti, M.P., Myers, M.G. Jr \& Ishikawa, Y. (1998) Caveolin is an activator of insulin receptor signaling. Journal of Biological Chemistry, 273, 26962-26968.

12 Nystrom, F.H., Chen, H., Cong, L.N., Li, Y. \& Quon, M.J. (1999) Caveolin-1 interacts with the insulin receptor and can differentially modulate insulin signaling in transfected Cos-7 cells and rat adipose cells. Molecular Endocrinology, 13, 2013-2024.

13 Souto, R.P., Vallega, G., Wharton, J., Vinten, J., Tranum-Jensen, J. \& Pilch, P.F. (2003) Immunopurification and characterization of rat adipocyte caveolae suggest their dissociation from insulin signaling. Journal of Biological Chemistry, 278, 18321-18329.

14 Wharton, J., Meshulam, T., Vallega, G. \& Pilch, P. (2005) Dissociation of insulin receptor expression and signalling from caveolin-1 expression. Journal of Biological Chemistry, 280, $13483-13486$.

15 Hotamisligil, G.S., Shargill, N.S. \& Spiegelman, B.M. (1993) Adipose expression of tumor necrosis factor a: direct role in obesity-linked insulin resistance. Science, 259, 87-91.

16 Tilg, H. \& Moschen, A.R. (2006) Adipocytokines: mediators linking adipose tissue, inflammation and immunity. Nature Reviews Immunology, 6, 772-783.

17 Gómez-Ambrosi, J., Salvador, J., Rotellar, F., Silva, C., Catalán, V., Rodríguez, A., Gil, M.J. \& Frühbeck, G. (2006) Increased serum amyloid A concentrations in morbid obesity decrease after gastric bypass. Obesity Surgery, 16, 262-269.

18 Jasmin, J.F., Mercier, I., Sotgia, F. \& Lisanti, M.P. (2006) SOCS proteins and caveolin-1 as negative regulators of endocrine signaling. Trends in Endocrinology and Metabolism, 17, $150-158$.

19 Garrean, S., Gao, X.P., Brovkovych, V., Shimizu, J., Zhao, Y.Y., Vogel, S.M. \& Malik, A.B. (2006) Caveolin-1 regulates NF-kappaB activation and lung inflammatory response to sepsis induced by lipopolysaccharide. Journal of Immunology, 177, 4853-4860.

20 Hotamisligil, G.S. (2006) Inflammation and metabolic disorders. Nature, 444, 860-867.

21 Gómez-Ambrosi, J., Salvador, J., Silva, C., Pastor, C., Rotellar, F., Gil, M.J., Cienfuegos, J.A. \& Frühbeck, G. (2006) Increased cardiovascular risk markers in obesity are associated with body adiposity: role of leptin. Thrombosis and Haemostais, 95, 991-996.

22 Gómez-Ambrosi, J., Catalán, V., Diez-Caballero, A., Martínez-Cruz, L.A., Gil, M.J., GarcíaFoncillas, J., Cienfuegos, J.A., Salvador, J., Mato, J.M. \& Frühbeck, G. (2004) Gene expression profile of omental adipose tissue in human obesity. FASEB Journal, 18, 215- 217. 
23 Catalán, V., Gómez-Ambrosi, J., Rotellar, F., Silva, C., Gil, M.J., Rodríguez, A., Cienfuegos, J.A., Salvador, J. \& Frühbeck, G. (2007) The obestatin receptor (GPR39) is expressed in human adipose tissue and is down-regulated in obesity-associated type 2 diabetes mellitus. Clinical Endocrinology, 66, 598-601.

24 Catalán, V., Gómez-Ambrosi, J., Rotellar, F., Silva, C., Rodríguez, A., Salvador, J., Gil, M.J., Cienfuegos, J.A. \& Frühbeck, G. (2007) Validation of endogenous control genes in human adipose tissue: relevance to obesity and obesity-associated type 2 diabetes mellitus. Hormone and Metabolic Research, 39, 495-500.

25 Wajchenberg, B.L. (2000) Subcutaneous and visceral adipose tissue: their relation to the metabolic syndrome. Endocrine Reviews, 21, 697-738.

26 Kersten, S. (2001) Mechanisms of nutritional and hormonal regulation of lipogenesis. EMBO Reports, 2, 282-286.

27 Saltiel, A.R. \& Kahn, C.R. (2001) Insulin signalling and the regulation of glucose and lipid metabolism. Nature, 414, 799-806.

28 Ishikawa, Y., Otsu, K. \& Oshikawa, J. (2005) Caveolin; different roles for insulin signal? Cell Signalling, 17, 1175-1182.

29 Inokuchi, J. (2006) Insulin resistance as a membrane microdomain disorder. Biology and Pharmaceutical Bulletin, 29, 1532-1537.

30 Foti, M., Porcheron, G., Fournier, M., Maeder, C. \& Carpentier, J.L. (2007) The neck of caveolae is a distinct plasma membrane subdomain that concentrates insulin receptors in 3T3-L1 adipocytes. Proceedings of the National Academy of Sciences of the USA, 104, 1242-1247.

31 Moller, D.E., Yokota, A., Ginsberg-Fellner, F. \& Flier, J.S. (1990) Functional properties of a naturally occurring Trp1200-Ser1200 mutation of the insulin receptor. Molecular Endocrinology, 4, 1183-1191.

32 Iwanishi, M., Haruta, T., Takata, Y., Ishibashi, O., Sasaoka, T., Egawa, K., Imamura, T., Naitou, K., Itazu, T. \& Kobayashi, M. (1993) A mutation (Trp1193 $\rightarrow$ Leu1193) in the tyrosine kinase domain of the insulin receptor associated with type A syndrome of insulin resistance. Diabetologia, 36, 414-422.

33 Fried, S.K., Bunkin, D., A. \& Greenberg, A.S. (1998) Omental and subcutaneous adipose tissues of obese subjects release interleukin-6: depot difference and regulation by glucocorticoid. Journal of Clinical Endocrinology and Metabolism, 83, 847-850.

34 Bruun, J.M., Lihn, A.S., Madan, A.K., Pedersen, S.B., Schiott, K.M., Fain, J.N. \& Richelsen, B. (2004) Higher production of IL-8 in visceral vs. subcutaneous adipose tissue: implication of nonadipose cells in adipose tissue. American Journal of Physiology: Endocrinology and Metabolism, 286, E8-E13.

35 van der Westhuyzen, D.R., Cai, L., de Beer, M.C. \& de Beer, F.C. (2005) Serum amyloid A promotes cholesterol efflux mediated by scavenger receptor B-I. Journal of Biological Chemistry, 280, 35890-35895. 
36 Frank, P.G., Cheung, M.W., Pavlides, S., Llaverias, G., Park, D.S. \& Lisanti, M.P. (2006) Caveolin-1 and regulation of cellular cholesterol homeostasis. American Journal of Physiology: Heart and Circulatory Physiology, 291, H677-H686.

37 Razani, B., Zhang, X.L., Bitzer, M., von Gersdorff, G., Bottinger, E.P. \& Lisanti, M.P. (2001) Caveolin-1 regulates transforming growth factor TGF R/SMAD signaling through an interaction with the TGF R type I receptor. Journal of Biological Chemistry, 276, 6727-6738.

38 Sehgal, P.B. (2003) Plasma membrane rafts and chaperones in cytokine/STAT signaling. Acta Biochimica Polonica, 50, 583-594.

39 Felley-Bosco, E., Bender, F.C., Courjault-Gautier, F., Bron, C. \& Quest, A.F. (2000) Caveolin-1 down-regulates inducible nitric oxide synthase via the proteasome pathway in human colon carcinoma cells. Proceedings of the National Academy of Sciences of the USA, 97, 14334-14339. 
Table 1. Anthropometric and biochemical characteristics of women included in the study

\begin{tabular}{|c|c|c|c|}
\hline & Lean & Obese NG & Obese T2DM \\
\hline$N$ & 5 & 5 & 5 \\
\hline Age (years) & $38 \pm 4$ & $36 \pm 5$ & $43 \pm 3$ \\
\hline BMI $\left(\mathrm{kg} / \mathrm{m}^{2}\right)$ & $20 \cdot 8 \pm 1 \cdot 0$ & $48 \cdot 4 \pm 2 \cdot 0^{*}$ & $52 \cdot 6 \pm 4 \cdot 9 *$ \\
\hline Body fat (\%) & $28 \cdot 1 \pm 3 \cdot 0$ & $56 \cdot 3 \pm 1 \cdot 1 \dagger$ & $55 \cdot 0 \pm 1 \cdot 8 \dagger$ \\
\hline Fasting glucose (mmol/1) & $5 \cdot 1 \pm 0 \cdot 2$ & $4 \cdot 9 \pm 0 \cdot 3$ & $7 \cdot 6 \pm 0 \cdot 6 \dagger \$$ \\
\hline 2 h OGTT glucose (mmol/l) & $6 \cdot 0 \pm 0 \cdot 6$ & $6 \cdot 4 \pm 0 \cdot 3$ & $14 \cdot 7 \pm 2 \cdot 4 \uparrow \$$ \\
\hline Fasting insulin (mmol/1) & $57 \cdot 7 \pm 12 \cdot 5$ & $140 \cdot 4 \pm 36 \cdot 7$ & $176 \cdot 3 \pm 49 \cdot 9 *$ \\
\hline $2 \mathrm{~h}$ OGTT insulin $(\mathrm{mmol} / \mathrm{l})$ & $81 \cdot 9 \pm 13 \cdot 3$ & $804 \cdot 2 \pm 333 \cdot 8^{*}$ & $707 \cdot 5 \pm 145 \cdot 1 *$ \\
\hline HOMA & $1 \cdot 7 \pm 0 \cdot 4$ & $4 \cdot 0 \pm 1 \cdot 1$ & $8 \cdot 1 \pm 2 \cdot 9 *$ \\
\hline QUICKI & $0 \cdot 363 \pm 0 \cdot 017$ & $0 \cdot 320 \pm 0 \cdot 013$ & $0 \cdot 297 \pm 0 \cdot 015 \dagger$ \\
\hline Cholesterol (mmol/l) & $4 \cdot 8 \pm 0 \cdot 3$ & $4 \cdot 8 \pm 0 \cdot 4$ & $5 \cdot 2 \pm 0 \cdot 3$ \\
\hline LDL-cholesterol (mmol/l) & $3 \cdot 4 \pm 0 \cdot 2$ & $3 \cdot 2 \pm 0 \cdot 3$ & $3 \cdot 5 \pm 0 \cdot 2$ \\
\hline HDL-cholesterol (mmol/1) & $1 \cdot 4 \pm 0 \cdot 1$ & $1 \cdot 0 \pm 0 \cdot 0 \dagger$ & $1 \cdot 0 \pm 0 \cdot 0 \dagger$ \\
\hline Leptin (ng/ml) & $9 \cdot 1 \pm 1 \cdot 7$ & $57 \cdot 6 \pm 7 \cdot 6^{*}$ & $69 \cdot 3 \pm 19 \cdot 6 \dagger$ \\
\hline Adiponectin $(\mu \mathrm{g} / \mathrm{ml})$ & $11 \cdot 2 \pm 2 \cdot 4$ & $8 \cdot 8 \pm 0 \cdot 8$ & $4 \cdot 8 \pm 0 \cdot 5^{*}$ \\
\hline C-reactive protein $(\mathrm{mg} / \mathrm{l})$ & $2 \cdot 00 \pm 0 \cdot 45$ & $6 \cdot 40 \pm 0 \cdot 81 \dagger$ & $8 \cdot 80 \pm 1 \cdot 36 \dagger$ \\
\hline Fibrinogen (g/l) & $2 \cdot 60 \pm 0 \cdot 34$ & $4 \cdot 04 \pm 0 \cdot 23 \dagger$ & $3 \cdot 41 \pm 0 \cdot 14^{*}$ \\
\hline $\mathrm{MCP}-1(\mu 1 / 1)$ & $107 \cdot 8 \pm 11 \cdot 5$ & $162 \cdot 6 \pm 18 \cdot 3 *$ & $178 \cdot 8 \pm 15 \cdot 0 \dagger$ \\
\hline $\mathrm{SAA}(\mathrm{mg} / \mathrm{l}) \S$ & $4 \cdot 7(3 \cdot 3-13 \cdot 2)$ & $28 \cdot 2(7 \cdot 9-30 \cdot 2)^{*}$ & $16 \cdot 5(8 \cdot 4-61 \cdot 7)^{*}$ \\
\hline $\mathrm{SA}(\mathrm{mmol} / \mathrm{l})$ & $29 \cdot 7 \pm 5 \cdot 1$ & $39 \cdot 4 \pm 3 \cdot 7$ & $46 \cdot 7 \pm 5 \cdot 0^{*}$ \\
\hline TNF-a $(\mu \mathrm{g} / 1)$ & $1 \cdot 0 \pm 0 \cdot 1$ & $1 \cdot 9 \pm 0.4^{*}$ & $1.9 \pm 0.2 *$ \\
\hline
\end{tabular}

Data are mean \pm SEM for normally distributed variables and median (interquartile range) for the skewed variable SAA. Differences between both groups were analysed by one-way anova followed by LSD tests. $* \mathrm{P}<0.05$ and $\dagger \mathrm{P}<0.01$ vs. lean. $\ddagger \mathrm{P}<0.01$ vs. NG obese. §SAA values were logarithmically transformed for statistical analysis.

NG, normoglycaemic; T2DM, type 2 diabetes mellitus; BMI, body mass index;

OGTT, oral glucose tolerance test; HOMA, homeostasis model assessment;

LDL, low-density lipoprotein; HDL, high-density lipoprotein;

MCP, monocyte chemoattractant protein; SAA, serum amyloid A; SA, sialic acid. 
Table 2. Univariate analysis of the correlation between caveolin-1 (CAV-1) mRNA and several inflammatory-related variables in visceral adipose tissue (VAT) and subcutaneous adipose tissue (SAT) unadjusted and after adjusting for age and body mass index (BMI)

\begin{tabular}{|c|c|c|c|c|c|c|}
\hline & \multicolumn{2}{|c|}{ Unadjusted } & \multicolumn{2}{|c|}{$\begin{array}{l}\text { Age- } \\
\text { adjusted }\end{array}$} & \multicolumn{2}{|c|}{$\begin{array}{l}\text { Age- and BMI- } \\
\text { adjusted }\end{array}$} \\
\hline & $r$ & $P$ & $r$ & $P$ & $r$ & $P$ \\
\hline \multicolumn{7}{|l|}{ VAT } \\
\hline BMI & $0 \cdot 58$ & $0 \cdot 030$ & $0 \cdot 63$ & $0 \cdot 022$ & - & - \\
\hline Body fat & $0 \cdot 66$ & $0 \cdot 010$ & $0 \cdot 78$ & $0 \cdot 002$ & $0 \cdot 71$ & $0 \cdot 010$ \\
\hline C-reactive protein & $0 \cdot 55$ & $0 \cdot 040$ & $0 \cdot 63$ & $0 \cdot 021$ & $0 \cdot 19$ & 0.554 \\
\hline SA & $0 \cdot 56$ & $0 \cdot 048$ & $0 \cdot 85$ & $<0.001$ & $0 \cdot 76$ & 0.007 \\
\hline SAA & $0 \cdot 63$ & $0 \cdot 022$ & $0 \cdot 59$ & $0 \cdot 041$ & $0 \cdot 11$ & 0.744 \\
\hline Fibrinogen & $0 \cdot 73$ & 0.003 & $0 \cdot 76$ & $0 \cdot 002$ & $0 \cdot 61$ & 0.033 \\
\hline \multicolumn{7}{|l|}{ SAT } \\
\hline BMI & $0 \cdot 95$ & $<0 \cdot 0001$ & $0 \cdot 91$ & $0 \cdot 001$ & - & - \\
\hline Body fat & $0 \cdot 89$ & $0 \cdot 001$ & $0 \cdot 84$ & $0 \cdot 005$ & $-0 \cdot 10$ & $0 \cdot 812$ \\
\hline C-reactive protein & $0 \cdot 90$ & $0 \cdot 001$ & $0 \cdot 87$ & 0.003 & $0 \cdot 25$ & 0.543 \\
\hline SA & $0 \cdot 73$ & $0 \cdot 017$ & $0 \cdot 68$ & $0 \cdot 044$ & $0 \cdot 29$ & $0 \cdot 490$ \\
\hline SAA & $0 \cdot 48$ & $0 \cdot 144$ & $0 \cdot 65$ & $0 \cdot 06$ & $-0 \cdot 83$ & 0.011 \\
\hline Fibrinogen & $0 \cdot 47$ & $0 \cdot 170$ & $0 \cdot 53$ & $0 \cdot 139$ & -0.07 & 0.859 \\
\hline
\end{tabular}

BMI, body mass index; SA, sialic acid; SAA, serum amyloid A. 
(a)
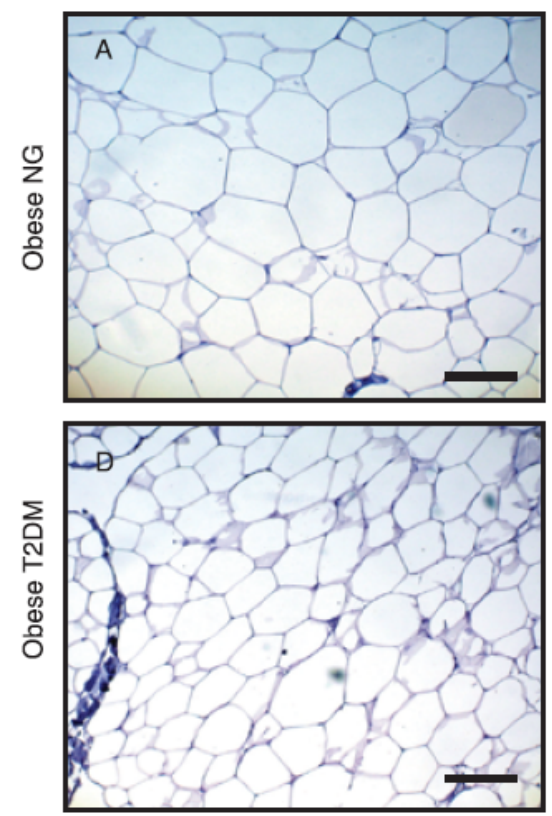

(b)
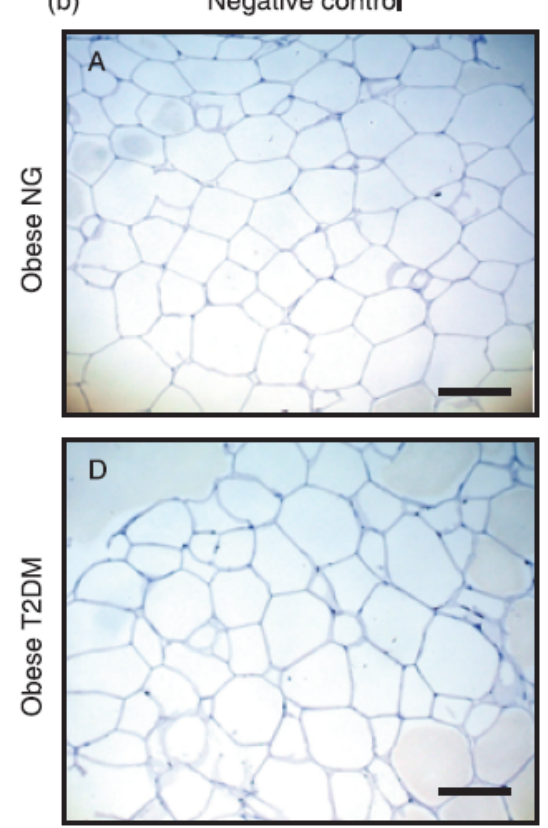

Visceral adipose tissue

Caveolin-1
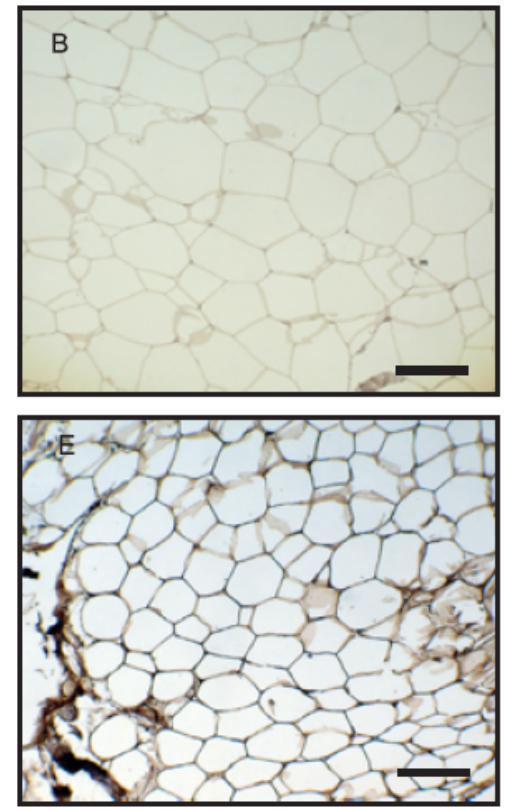

Subcutaneous adipose tissue

Caveolin-1
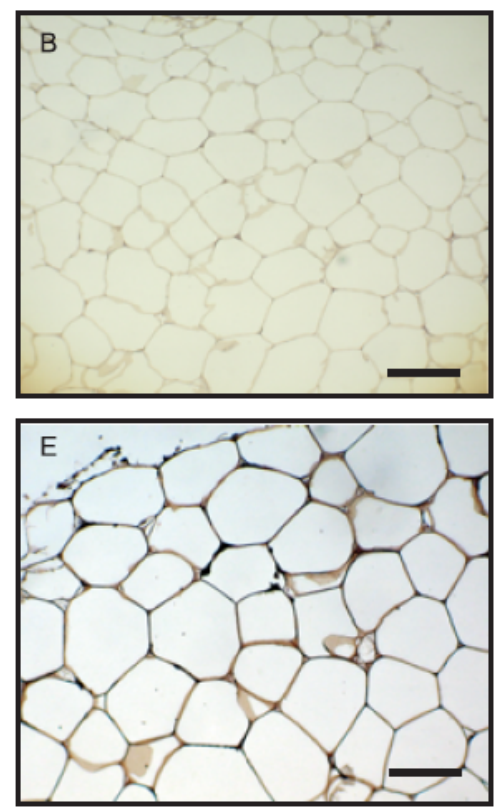

Caveolin-1
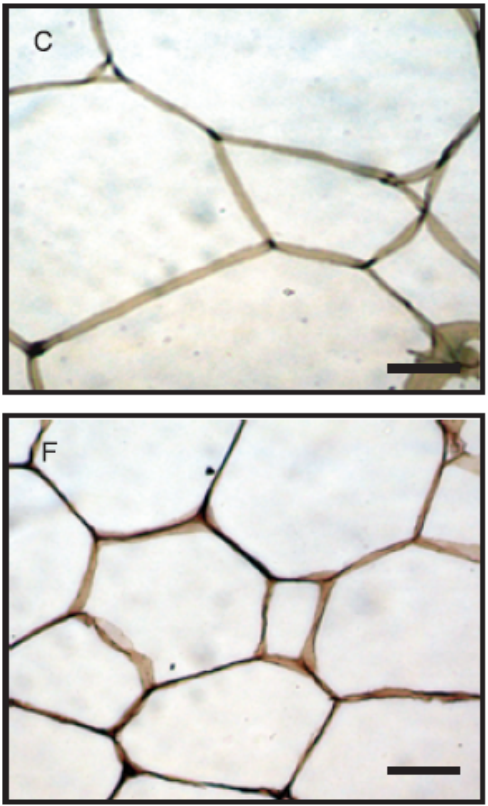

Caveolin-1
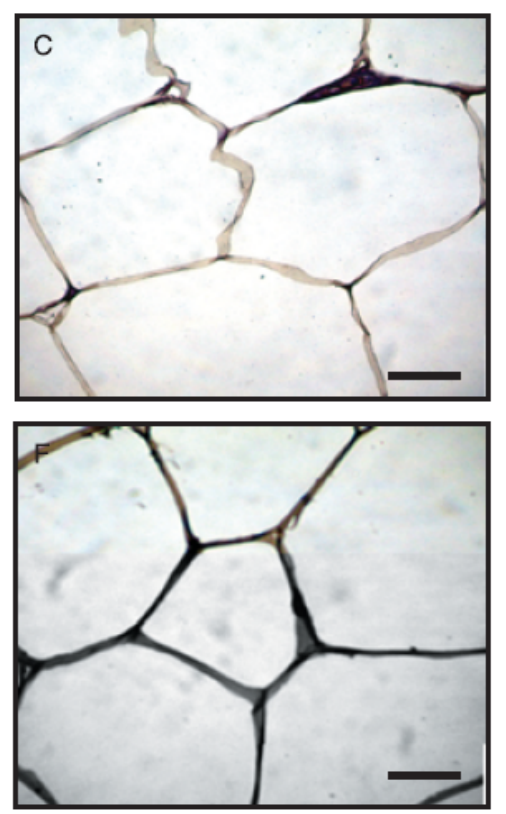

Fig. 1 Immunostaining of CAV-1 in human (a) visceral adipose tissue (VAT) and (b) subcutaneous adipose tissue (SAT) of normoglycaemic (NG) and type 2 diabetes mellitus (T2DM) obese patients. Strong positivity (brown staining) was observed for CAV-1 in both fully mature adipocytes and cells of the stromovascular fraction of SAT and VAT (B, C, E and F). No immunoreactivity was found without the primary antibody (negative control) (A and D). Images are representative of immunostaining in VAT and SAT from 6 obese subjects. A, B, D and E: $\times$ $100($ scale bar $=80 \mu \mathrm{m}) ; \mathrm{C}$ and $\mathrm{F}: \times 400($ scale bar $=20 \mu \mathrm{m})$. 


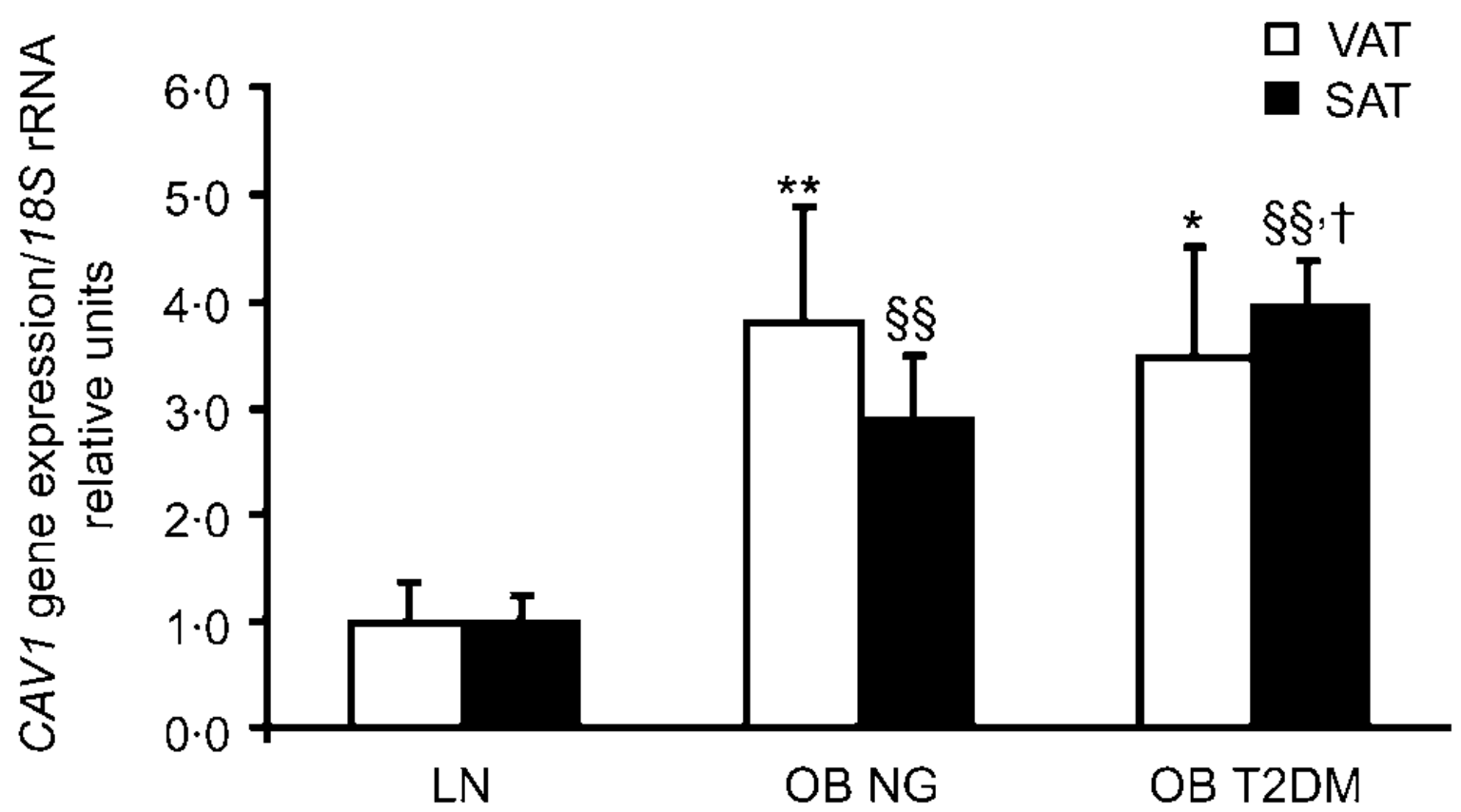

Fig. 2 Real-time polymerase chain reaction (PCR) analysis of CAV-1 transcript levels in visceral adipose tissue (VAT) and subcutaneous adipose tissue (SAT) of lean (LN), obese normoglycaemic (OB NG) and obese type 2 diabetes mellitus (OB T2DM) volunteers. Bars represent the mean \pm SEM of the ratio between CAV-1-18S rRNA. The expression of CAV-1 in lean subjects was assumed to be 1 . Differences between groups were analysed by one-way anova followed by LSD tests. $* \mathrm{P}<0.05$ and $* * \mathrm{P}<0.01$ vs. LN regarding CAV-1 expression levels in VAT and $\S \S \mathrm{P}<0.01$ vs. $\mathrm{LN}$ in SAT. $\uparrow \mathrm{P}<0.05$ vs. OB NG $(\mathrm{N}=5$ per group $)$. 